\title{
BEYOND BINARY CHOICES: UNDERSTANDING AND EXPLOITING TRADE-OFFS TO ENHANCE CREATIVITY
}

\author{
GERHARD FISCHER \\ Center for Lifelong Learning and Design (L3D) \\ University of Colorado, Boulder, USA \\ gerhard@colorado.edu
}

\begin{abstract}
Many research approaches are conceptualized as binary choices, representing endpoints of a spectrum (each of them providing important perspectives within their own discourses). Design and creativity are often conceptualized as being focused on one of these binary choices, thereby overlooking other possibilities. To better stimulate, enhance, and support creativity, our research has explored the middle ground between the endpoints defined by binary choices to identify "sweet spots" based on a careful trade-off analysis of specific goals, objectives, stakeholders, and socio-technical environments.

This paper illustrates some of the major trade-offs related to design and creativity that we have explored in our research over the last ten years, including prescriptive and permissive environments, individual and social creativity, communities of practice and communities of interest, and consumer and active contributor cultures. It briefly describes some of the socio-technical environments that we have developed to enhance creativity in specific contexts.
\end{abstract}

Keywords. creativity, individual and social creativity, design, metadesign, binary choices, consumers and producers, communities of practice, communities of interest, domain-oriented design environments, critiquing systems, Envisionment and Discovery Collaboratory, courses-as-seeds

\section{Introduction}

Our research over the last decade is grounded in conceptual frameworks and system building efforts characterized by the following global objectives:

- empowering users rather than replacing or deskilling them by emphasizing knowledge-based support environments from an intelligence augmentation perspective [Bobrow, 1991; Fischer \& Nakakoji, 1992]; 
- advancing human-computer interaction to human problem-domain interaction, by putting owners of problems in charge with domainoriented design environments [Fischer, 1994];

- $\quad$ transcending desktop-based computing by integrating physical and computational environments [Arias et al., 2000];

- $\quad$ supporting reflective practitioners with critiquing systems by increasing the back-talk of design artifacts and linking action and reflection spaces [Fischer et al., 1998; Schön, 1983];

- creating open and evolvable systems grounded in the seeding, evolutionary growth, reseeding process model and supported by metadesign [Fischer et al., 2004a; Fischer et al., 2001]; and

- understanding design as a dialectical process between tradition and transcendence by showing how the tension between old and new in computational artifacts can serve as a driving force of evolutionary developments. Emphasis on tradition reduces the impact of new media to "gift-wrapping," and ignorance of tradition leads to "technodeterminism" [Ehn, 1988; Fischer, 1998].

\section{Binary Choices}

Trade-offs are the most basic characteristics in design: they are, in fact, universal. There are no best solutions independent of goals and objectives [Simon, 1996]. Trade-offs are often characterized and conceptualized as binary choices. Binary choices represent the endpoints of a spectrum (each of them providing important perspectives within their own discourses). Exploring the middle ground between these endpoints, however, will help one to gain a deeper understanding of what stifles and hinders versus stimulates and enhances creativity. Identifying "sweet spots" as a combination of factors allowing for a particular suitable solution in a specific context and synergizing the best of the different approaches will enhance further progress. Csikszentmihalyi [Csikszentmihalyi, 1996] discusses personality characteristics of creative people who "definitely know both extremes and experience both with equal intensity and without inner conflict." Some examples described by Csikszentmihalyi are (1) being smart and naïve at the same time; (2) a combination of playfulness and discipline, or responsibility and irresponsibility; (3) an alternation between imagination at one end and a rooted sense of reality at the other; and (4) being rebellious and independent, but having internalized a domain of culture.

Creativity is a complex phenomenon, as indicated in part by the personality characteristics mentioned. Any socio-technical environment that supports and enhances creativity must therefore be based on a multidimensional framework and architecture. Table 1 provides an overview of some of the major binary choices that we have encountered and tried to 
overcome in our research (the trade-offs discussed in detail in sections 3.1 3.5 of this paper are highlighted in bold).

TABLE 1: Integrating Binary Choices and Finding Partial Resolutions

\begin{tabular}{|c|c|c|}
\hline Choice-1 & Choice-2 & Choice-3 (Partial Resolution) \\
\hline $\begin{array}{l}\text { tool-based } \\
\text { assistance }\end{array}$ & agent-based assistance & $\begin{array}{l}\text { domain-oriented design } \\
\text { environments [Shneiderman \& Maes, } \\
\text { 1997] }\end{array}$ \\
\hline $\begin{array}{l}\text { generic ("Turing } \\
\text { Tar Pit") }\end{array}$ & $\begin{array}{l}\text { domain-oriented (over- } \\
\text { specialized systems) }\end{array}$ & layered architectures [Fischer, 1994] \\
\hline tradition & transcendence & $\begin{array}{l}\text { dialectical process between the two } \\
\text { objectives [Ehn, 1988] }\end{array}$ \\
\hline $\begin{array}{l}\text { descriptions, } \\
\text { requirements }\end{array}$ & emergence, evolution & $\begin{array}{l}\text { seeding, evolutionary growth, } \\
\text { reseeding [Fischer et al., 2001] }\end{array}$ \\
\hline serendipity & $\begin{array}{l}\text { relevancy to the task at } \\
\text { hand }\end{array}$ & $\begin{array}{l}\text { provide both and let users choose } \\
\text { [Roberts, 1989] }\end{array}$ \\
\hline $\begin{array}{l}\text { extrinsic } \\
\text { motivation }\end{array}$ & intrinsic motivation & social capital [Florida, 2002] \\
\hline $\begin{array}{l}\text { novice/student/ } \\
\text { employee }\end{array}$ & expert/teacher/manager & $\begin{array}{l}\text { collaborative advancement of } \\
\text { knowledge [Rogoff et al., 1998] }\end{array}$ \\
\hline physical & computational & augmented reality [Arias et al., 2000] \\
\hline action & reflection & reflection-in-action [Schön, 1983] \\
\hline discipline & agility & $\begin{array}{l}\text { risk-driven approach [Boehm \& } \\
\text { Turner, 2004] }\end{array}$ \\
\hline $\begin{array}{l}\text { access (pull; } \\
\text { passive critics) }\end{array}$ & $\begin{array}{l}\text { delivery (push; active } \\
\text { critics) }\end{array}$ & mixed-initiative [Horvitz, 1999] \\
\hline human support & computational support & $\begin{array}{l}\text { socio-technical environments } \\
\text { [Mumford, 1987] }\end{array}$ \\
\hline prescriptive & permissive & $\begin{array}{l}\text { guided discovery learning, } \\
\text { contextualized tutoring [Mayer, } \\
2004]\end{array}$ \\
\hline individual & social & $\begin{array}{l}\text { integration of individual and social } \\
\text { [Fischer et al., 2005] }\end{array}$ \\
\hline $\begin{array}{l}\text { communities of } \\
\text { practice }\end{array}$ & $\begin{array}{l}\text { communities of } \\
\text { interests }\end{array}$ & $\begin{array}{l}\text { epistemological pluralism [Turkle } \\
\text { \& Papert, 1991] }\end{array}$ \\
\hline $\begin{array}{l}\text { consumers } \\
\text { (focused on use) }\end{array}$ & $\begin{array}{l}\text { active contributors } \\
\text { (focused on design) }\end{array}$ & $\begin{array}{l}\text { end-user development [Fischer, } \\
\text { 2002] }\end{array}$ \\
\hline closed systems & open systems & $\begin{array}{l}\text { meta-design [Lieberman et al., } \\
\text { 2005] }\end{array}$ \\
\hline
\end{tabular}




\section{Examples of Trade-Offs}

\subsection{PRESCRIPTIVE VERSUS PERMISSIVE}

Creativity is often associated with transcending the information given and exploring unknown territory. But transcending often implies that we acquire a deep understanding of what exists. People unfamiliar with domains will not develop creative extensions for them [Csikszentmihalyi, 1996]. The prescriptive/permissive trade-off can be explored in several interesting contexts, including: internal and external scripts [Schank \& Abelson, 1977]; use of checklists in design environments [Lemke, 1989]; workflow systems in computer-supported collaborative work (CSCW) [Ellis et al., 1991]; and the act of learning and learning environments, which will be used here for further illustration.

Self-directed Learning and Tutoring. One specific area in which the relationship between prescriptive and permissive approaches can be explored is learning. Here we contrast self-directed learning (being primarily permissive, often embedded in constructionist approaches) with tutoring (being primarily prescriptive, often embedded in instructionist approaches). The challenge is to identify a middle ground-learners need enough freedom to choose what to learn and how to learn it and enough guidance to explore and construct useful knowledge. If pursued independently, self-directed learning and tutoring suffer shortcomings. For example, self-directed learning, conceived as pure discovery learning, has the substantial weakness that learners are not exposed to coherent presentations of disciplinary knowledge, and thus remain stuck at suboptimal plateaus. Tutoring, without being contextualized, is not responsive to the real needs and interests of learners.

Tutoring and self-directed learning are grounded in contradictory educational approaches (see TABLE 2):

- Tutoring is based on the assumptions that (1) the structure of a discipline is an accumulation of the fundamental ideas that enabled a scholar to proceed [Bruner, 1960]; (2) providing one-to-one instruction is effective [Mandl \& Lesgold, 1988]; and (3) society can define a coherent body of knowledge that everyone should master [Hirsch, 1996].

- Self-directed learning is based on the assumptions that (1) student interests are central [Dewey, 1967]; (2) people learn best when engrossed in a topic, or when motivated to seek out new knowledge and skills to solve a problem at hand [Csikszentmihalyi et al., 1993; Norman, 1993]; and (3) people in personally meaningful activities want to learn more and act as active contributors, not just as passive consumers [Fischer, 2002]. 
What is needed but mostly lacking is moving beyond binary choices: self-directed learning and tutoring are endpoints in a broad spectrum of possible approaches. Concepts such as guided discovery learning [Mayer, 2004] and community of learners [Rogoff et al., 1998] illustrate different approaches and show that opportunities exist to exploit the best of both possible worlds.

TABLE 2: Distinctions and Complementary Nature of Tutoring and Self-Directed Learning

\begin{tabular}{|c|c|c|}
\hline \multicolumn{2}{|r|}{ Tutoring } & \multirow{2}{*}{$\begin{array}{l}\text { Self-Directed Learning } \\
\text { problem is based on the } \\
\text { learner's needs and interest; } \\
\text { learning supported from the } \\
\text { demand side; child-run } \\
\text { education; permissive }\end{array}$} \\
\hline characteristics & $\begin{array}{l}\text { problem is given by the } \\
\text { teacher or the systems; } \\
\text { learning supported from the } \\
\text { supply side; adult-run } \\
\text { education; prescriptive }\end{array}$ & \\
\hline strengths & $\begin{array}{l}\text { organized body of } \\
\text { knowledge; pedagogically } \\
\text { and cognitively structured } \\
\text { presentations }\end{array}$ & $\begin{array}{l}\text { real interests, personally } \\
\text { meaningful tasks, high } \\
\text { motivation }\end{array}$ \\
\hline weaknesses & $\begin{array}{l}\text { limited relevancy to the } \\
\text { interests of the learner or the } \\
\text { task at hand }\end{array}$ & $\begin{array}{l}\text { coverage of important } \\
\text { concepts may be missing; } \\
\text { demand driven, unstructured } \\
\text { learning episodes; lack of } \\
\text { coherence }\end{array}$ \\
\hline $\begin{array}{l}\text { primary role of the } \\
\text { teacher }\end{array}$ & $\begin{array}{l}\text { sage on the stage — presents } \\
\text { what he/she knows and is } \\
\text { prepared for }\end{array}$ & $\begin{array}{l}\text { guide on the side -answers } \\
\text { and relevant information have } \\
\text { to be culled from questions } \\
\text { posed by others }\end{array}$ \\
\hline $\begin{array}{l}\text { planning versus } \\
\text { situated responses }\end{array}$ & $\begin{array}{l}\text { anticipating and planning of } \\
\text { the learning goals and content }\end{array}$ & $\begin{array}{l}\text { learning needs arise from the } \\
\text { situational context }\end{array}$ \\
\hline $\begin{array}{l}\text { distribution over } \\
\text { lifetime }\end{array}$ & $\begin{array}{l}\text { decreasing in importance } \\
\text { from school to university to } \\
\text { lifelong learning }\end{array}$ & $\begin{array}{l}\text { increasing in importance } \\
\text { from school to university to } \\
\text { lifelong learning }\end{array}$ \\
\hline assessment & $\begin{array}{l}\text { "standard" assessment } \\
\text { instruments are applicable }\end{array}$ & $\begin{array}{l}\text { "innovative" assessment } \\
\text { instruments are needed }\end{array}$ \\
\hline $\begin{array}{l}\text { unique research } \\
\text { challenges }\end{array}$ & $\begin{array}{l}\text { presentation of an organized } \\
\text { body of knowledge; } \\
\text { responsiveness in the teacher- } \\
\text { defined context to individual } \\
\text { differences }\end{array}$ & $\begin{array}{l}\text { task identification; context } \\
\text { awareness; large repository of } \\
\text { tutoring episodes }\end{array}$ \\
\hline
\end{tabular}




\subsection{INDIVIDUAL VERSUS SOCIAL CREATIVITY}

The Need for Multiple Voices in Design. Social creativity explores computer media and technologies to help people work together. It is relevant to design because collaboration plays an increasingly significant role in design projects that require expertise in a wide range of domains. Software design projects, for example, involve designers, programmers, humancomputer interaction specialists, marketing people, and end-user participants [Greenbaum \& Kyng, 1991]. Information technologies have reached such a level of sophistication, maturity, cost-effectiveness, and distribution that they are not restricted to only enhancing productivity - they also open up new creative possibilities [National Research Council, 2003].

Design projects may take place over many years, with initial design followed by extended periods of evolution and redesign. In this sense, design artifacts are not designed once and for all, but instead they evolve over long periods of time [Fischer, 2005] during which designers may extend or modify artifacts designed by people they have never met.

In extended and distributed design projects, specialists from many different domains must coordinate their efforts despite large separations of time and distance. In such projects, collaboration is crucial for success, yet it is difficult to achieve. Complexity arises from the need (1) to synthesize different perspectives, (2) to exploit collisions between concepts and ideas coming from different disciplines, (3) to manage large amounts of information potentially relevant to a design task, and (4) to understand the design decisions that have determined the long-term evolution of a designed artifact. Social creativity does not necessitate the development of environments in which the interests of the many inevitably supersede those of the individual. Appropriate socio-technical settings can amplify the outcome of a group of creative people by both augmenting individual creativities and multiplying rather than simply summing up individual creativities [Fischer et al., 2005].

Individual Creativity. Creative individuals, such as movie directors, leaders of sports teams, and leading scientists and politicians, can make a huge difference in exemplary cases. Individual creativity is grounded in the unique perspective that the individual brings to bear in the current problem or situation. It is the result of the life experience, culture, education, and background knowledge of the individual, as well as the individual's personal interest associated with a particular situation. Individual creativity, however, has limits. In today's society, the Leonardesque aspiration to have people who are competent in all of science has to fail because the individual human mind is limited [Campbell, 2005; Shneiderman, 2002].

Individuals may have the following concerns related to their voices being heard: 
"Am I interested enough and am I willing to make the additional effort and time so my voice is heard?" - This relates to what motivates people to participate (e.g., to vote in an election, to engage in a neighborhood association). Participation is more likely in cases in which people are engaged in personally meaningful problems [Fischer, 2002].

"Do I have something relevant to say?" - The local voices and unique expertise are often especially valuable in a global world; the incredible diversity of building styles, restaurants, food, and hotels that exist in different parts of the world are jeopardized and in some cases destroyed by the rise of tourism and the global marketplace [Friedman, 2005].

"Am I able to express what I want to say?" - Owners of problems need to be independent of high-tech scribes; this requires literacy, and in the world today, where ideas and work products are documented with computers, it requires digital fluency [National Research Council, 1999].

"Am I able and willing to express myself in a way that others can understand what I am saying?" - This is relevant in (1) participatory design processes in which people should express themselves with boundary objects [Star, 2005] rather than with their own respective technical jargon, and (2) efforts so the public can understand the work of the scientists.

Social Creativity. Creative activity grows out of the relationship between an individual and the world of his or her work, as well as from the ties between an individual and other human beings. Much human creativity arises from activities that take place in a social context in which interaction with other people and the artifacts that embody group knowledge are important contributors to the process. Creativity happens not inside a person's head, but in the interaction between a person's thoughts and a sociocultural context [Csikszentmihalyi, 1996].

A group, community, or society is interested in hearing as many voices as possible for the following concerns:

"How can we encourage individuals to contribute to the good and progress of all of us?" - This is relevant in open source efforts, which rely on social capital and gift cultures [Fischer et al., 2004b].

"In order to stimulate and increase social creativity, how can we support and exploit cultural pluralism and epistemological pluralism as an advantage rather than as a disadvantage?" - Related questions include: Is the European multi-culturalism and its local and regional identities a strength or a weakness? Are we willing to accept the validity and the multiple ways of knowing and thinking, especially by including the voices of underrepresented and underprivileged groups (e.g., people with disabilities [Carmien et al., 2004])?

"How do we avoid the situation that voices get lost because there is too much information or their input does not get recorded?" - In other words, how do we create knowledge management environments that support the right 
division between pull and push technologies and that have some context awareness?

"How do we avoid illegitimate voices?" — this includes information that is pushed at people without their consent (such as spam mail) or is made available against their will (such as violation of privacy).

"How do we avoid getting stuck in group think?" — This includes seeing controversy as an asset rather than as a limitation; group think [Janis, 1972] is especially harmful if some groups believe that their way of thinking is on top, rather than on tap [Turkle \& Papert, 1991].

"How do we eliminate sources of exclusion?" - This includes not only rules that specifically exclude people (such as minorities, lay persons facing experts, or people with disabilities), but ways of thinking and organizing that make them reluctant to join in.

Integrating Individual and Social Creativity. Our work is grounded in the basic belief that there is an "and" and not a "versus" relationship between individual and social creativity [Fischer et al., 2005]. Creativity occurs in the relationship between an individual and society, and between an individual and his or her technical environment. The mind, rather than driving on solitude, is clearly dependent upon the reflection, renewal, and trust inherent in sustained human relationships [John-Steiner, 2000]. We need to support this distributed fabric of interactions by integrating diversity, making all voices heard, increasing the back-talk of the situation, and providing systems that are open and transparent, so that people can be aware of and access each other's work, relate it to their own work, transcend the information given, and contribute the results back to the community. This process is illustrated (in part at least) by the "location, comprehension, and modification" cycle in software reuse [Ye \& Fischer, 2005], the "collect/relate/create/donate" model [Shneiderman, 2002], and by the decentralized development process of open source communities [Scharff, 2002].

Individual and social creativity can be integrated by means of proper collaboration models [Olson et al., 2001], appropriate community structures [Wenger, 1998], boundary objects [Star, 2005], process models in support of natural evolution of artifacts [Fischer et al., 2001], and meta-design [Fischer et al., 2004a]. By integrating individual and social creativity, support will be provided not only for reflective practitioners but also for reflective communities. Even within disciplines, competence is not achieved in individual minds, but as a collective achievement made possible by the overlap of narrow specialties [Campbell, 2005]. 


\subsection{COMMUNITIES OF PRACTICE VERSUS COMMUNITIES OF INTEREST}

"The clashing point of two subjects, two disciplines, two cultures ought to produce creative chaos." C.P. Snow [Snow, 1993]

Design communities are increasingly characterized by a division of labor [Levy \& Murnane, 2004], comprising individuals who have unique experiences, varying interests, and different perspectives about problems, and who use different knowledge systems in their work [Bonifacio \& Molani, 2003]. Shared understanding [Resnick et al., 1991] that supports collaborative learning and working requires the active construction of a knowledge system in which the meanings of concepts and objects can be debated and resolved. In heterogeneous design communities that form around large and complex design problems, the construction of shared understanding requires the interaction and synthesis of several separate knowledge systems [Turkle \& Papert, 1991].

Diversity is not only a constraint to deal with but an opportunity to generate new ideas, new insights, and new environments [Basalla, 1988; National Research Council, 2003]. The challenge is often not to reduce heterogeneity and specialization, but to support it, manage it, and integrate it by finding ways to build bridges between local knowledge and by exploiting conceptual collisions and breakdowns as sources for innovation.

Communities of Practice (CoPs) [Fischer, 2001b; Wenger, 1998] are homogeneous design communities consisting of practitioners who work as a community in a certain domain undertaking similar work. Traditional learning and working environments (e.g., university departments and their respective curricula) are disciplinary. Throughout history, the use of disciplines and their associated development of a division of labor have proven to be powerful approaches. However, we know from all the attempts to support multidisciplinary work that "real" problems can only rarely be successfully approached by a lone discipline [Campbell, 2005; Derry \& Fischer, 2005].

Communities of Interest (CoIs) [Fischer, 2001a] are heterogeneous design communities bringing together stakeholders from different CoPs to solve a particular (design) problem of common concern. They can be thought of as "communities of communities" [Brown \& Duguid, 1991] or communities of representatives of communities. Examples of CoIs are (1) a team of software designers, marketing specialists, psychologists, and programmers interested in software development; or (2) a group of citizens and experts interested in urban planning, in particular, in implementing new transportation systems. CoIs are supported by the Envisionment and Discovery Collaboratory [Arias et al., 2000] (see section 4), an integrated physical and computational environment supporting informed participation 
through new forms of knowledge creation, integration, and dissemination. Fundamental challenges facing CoIs are found in building a shared understanding [Resnick et al., 1991] of the task at hand, which often does not exist at the beginning but is evolved incrementally and collaboratively and emerges in people's minds and in external artifacts. Members of CoIs must learn to communicate with and learn from others [Derry et al., 2005; Engeström, 2001] who have different perspectives and perhaps different vocabularies to describe their ideas in order to establish a common ground [Clark \& Brennan, 1991].

Comparing CoPs and CoIs. TABLE 3 characterizes and differentiates CoPs and CoIs along a number of dimensions. The point of comparing and contrasting CoPs and CoIs is not to pigeonhole groups into either category, but rather to identify patterns of practice and helpful technologies. People can participate in more than one community, or one community can exhibit attributes of both a CoI and a CoP.

TABLE 3: Differentiating CoPs and CoIs

\begin{tabular}{|c|c|c|}
\hline Dimensions & CoPs & CoIs \\
\hline $\begin{array}{l}\text { nature of } \\
\text { problems }\end{array}$ & different tasks in the same domain & $\begin{array}{l}\text { common task across multiple } \\
\text { domains }\end{array}$ \\
\hline $\begin{array}{l}\text { knowledge } \\
\text { development }\end{array}$ & $\begin{array}{l}\text { refinement of one knowledge } \\
\text { system; new ideas coming from } \\
\text { within the practice }\end{array}$ & $\begin{array}{l}\text { synthesis and mutual learning } \\
\text { through the integration of } \\
\text { multiple knowledge systems }\end{array}$ \\
\hline $\begin{array}{l}\text { major } \\
\text { objectives }\end{array}$ & $\begin{array}{l}\text { codified knowledge, domain } \\
\text { coverage }\end{array}$ & $\begin{array}{l}\text { shared understanding, making } \\
\text { all voices heard }\end{array}$ \\
\hline weaknesses & group-think & lack of a shared understanding \\
\hline strengths & shared ontologies & $\begin{array}{l}\text { social creativity; diversity; } \\
\text { making all voices heard }\end{array}$ \\
\hline people & $\begin{array}{l}\text { beginners and experts; apprentices } \\
\text { and masters }\end{array}$ & $\begin{array}{l}\text { stakeholders (owners of } \\
\text { problems) from different } \\
\text { domains }\end{array}$ \\
\hline learning & legitimate peripheral participation & informed participation \\
\hline
\end{tabular}

Our Center for LifeLong Learning and Design (L3D) is an example: it has many characteristics of a $\mathrm{CoP}$ (having developed its own stories, terminology, and artifacts), but by actively engaging with people from outside our community (e.g., other colleges on campus, people from industry, international visitors, and so forth), it also has many characteristics of a CoI. Design communities do not have to be strictly either CoPs or CoIs; they can integrate aspects of both forms of communities. The community 
type may shift over time, according to events outside the community, the objectives of its members, and the structure of the membership.

CoPs are biased toward communicating with the same people and taking advantage of a shared background. The existence of an accepted, wellestablished center of expertise and a clear path of learning toward this center allows the differentiation of members into novices, intermediates, and experts. It makes these attributes viable concepts associated with people and provides the foundation for legitimate peripheral participation as a workable learning strategy. Some limitations of CoPs are that group-think [Janis, 1972] can suppress exposure to, and acceptance of, outside ideas; and the more someone is at home in a CoP, the more that person forgets the strange and contingent nature of its categories from the outside.

CoIs have a potential for creativity because different backgrounds and different perspectives can lead to new insights [Bennis \& Biederman, 1997]. They can support pluralistic societies by coping with complexity, contradictions, and a willingness to allow for differences of opinion. A fundamental barrier for CoIs might be that the participants fail to create common ground and shared understanding. This barrier is particularly challenging because CoIs often are more temporary than CoPs; they come together in the context of a specific project and dissolve after the project has ended.

\subsection{CONSUMER VERSUS PRODUCER CULTURES}

The process of knowledge accumulation in society has undergone major changes. Initially, knowledge was accumulated in the heads of people and communicated by tales, stories, and myths. The oral tradition has been replaced by a written tradition that allows people to permanently record thoughts and widely distribute them [Ong, 1982]. Information technologies [Hippel, 2005] have created fundamentally new opportunities, new challenges, and new problems for knowledge creation, integration, and dissemination, including open source communities [Fischer et al., 2004b; Raymond \& Young, 2001] and collaboratively constructed online encyclopedias such as Wikipedia (http://wikipedia.org/). The amount of available information and knowledge is exploding, and because information and knowledge consume attention, we all are suffering from it.

In our research we have developed a number of basic conceptual frameworks to support new ways to accumulate knowledge and selectively distribute it, including:

- the Seeding/Location/Comprehension/Modification/Sharing model instantiated by the Codebroker system [Ye \& Fischer, 2005];

- the Seeding/Evolutionary Growth/Reseeding model [Fischer et al., 2001]; and 
- $\quad$ the meta-design framework [Fischer et al., 2004a].

These approaches are related to: (1) the collect/relate/create/donate model of Shneiderman [Shneiderman, 2002]; (2) the basic assumption that information has a social life [Brown \& Duguid, 2000]; and (3) the ideas of convivial tools and deprofessionalization [Illich, 1973].

Professionally Dominated Cultures. A professionally dominated culture is characterized by a small number of experts and a large number of consumers (see Figure 1). Based on strong input filters (e.g., low acceptance rates for conferences and journals), relatively small information repositories are created. The advantage is the likelihood that the quality and trustworthiness of the accumulated information is high; thus, relatively weak output filters are required. The disadvantage of this model is that it greatly limits that "all voices can be heard," that most people are limited to accessing existing information, and that potentially relevant information (which may be of great value not at a global level but for the work of specific individuals) may not be incorporated into the information repository.

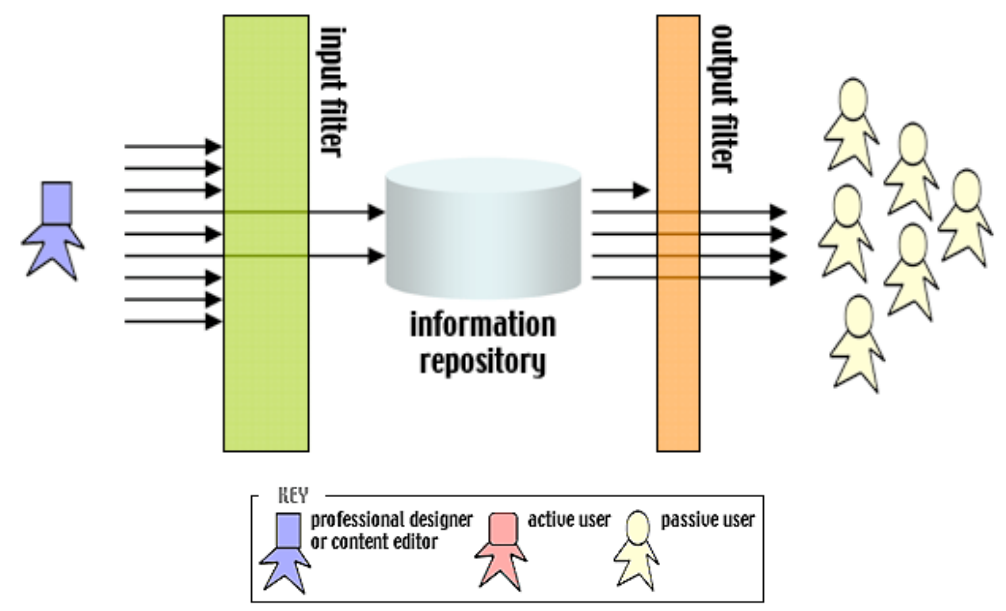

Figure 1: Producer/Consumer Relationships in a Professionally Dominated Culture

Design Cultures. Design cultures can be characterized by weak input filters, which allow users to not only access information but to become active contributors by engaging in informed participation [Brown et al., 1994]. The resulting information repositories (see Figure 2) are much larger (the World Wide Web is the prime example of this approach). Major limitations of this model are the potentially reduced trust and reliability of the content of the information repositories. This requires powerful search mechanisms to find relevant information and strong new output filters to allow users to judge the reliability of the information. 


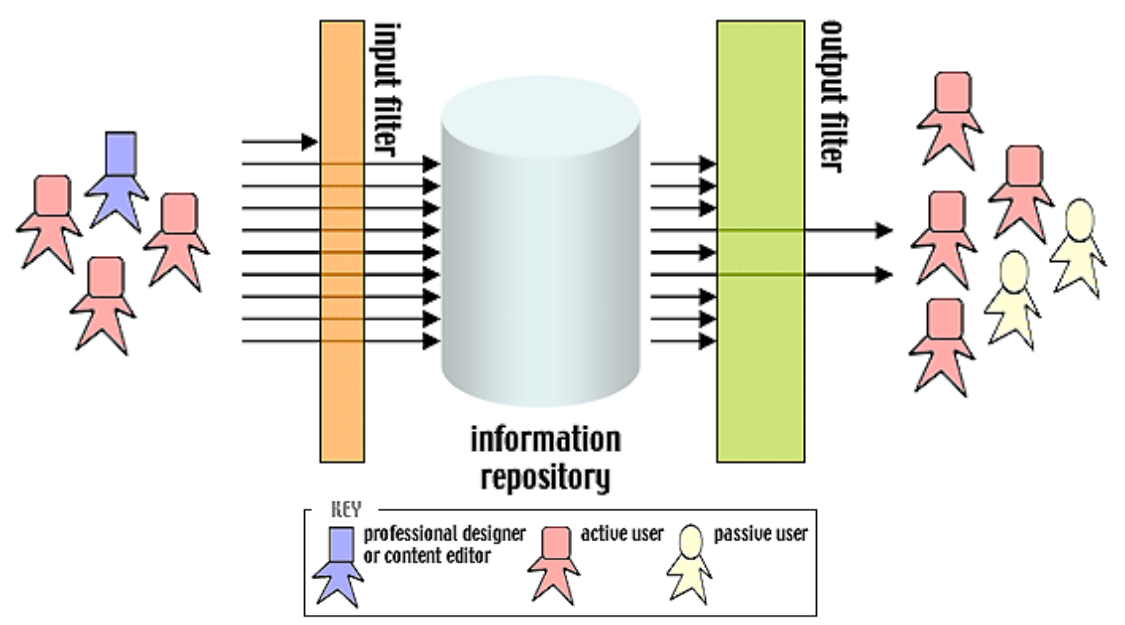

Figure 2: Producer/Consumer Relationships in a Design Culture

This brief characterization of the two models shows that both have strengths and weaknesses, and both serve as the guiding principles in different settings. Figure 3 illustrates how the proceedings of conferences - the CHI conference (white book) using strong input filters and the HCI International conference (dark books) using weak input filters-document their results in very different ways, depending on the basic criteria established by the respective meetings.

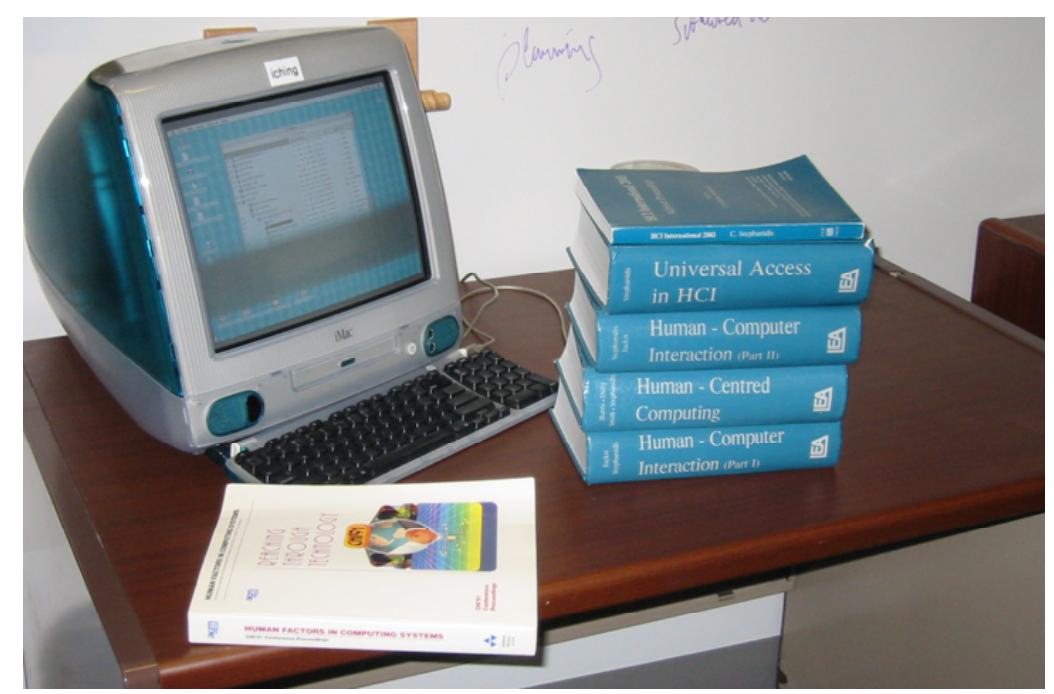

Figure 3: The Proceedings of Two Conferences 


\subsection{META-DESIGN: BEYOND CLOSED AND OPEN SYSTEMS}

Meta-design [Fischer et al., 2004a] characterizes objectives, techniques, and processes to allow users to act as designers by creating new knowledge rather than restricting them to the consumption of existing knowledge. Metadesign allows creative and unplanned opportunism, supports reflective communities, and addresses one of the fundamental challenges of a knowledge society: to invent and design a culture in which all participants in a collaborative design process can express themselves and engage in personally meaningful activities [Hippel, 2005].

The need for meta-design is founded on the observation that design requires open systems that users can modify and evolve. Because problems cannot be completely anticipated at design time when the system is developed, users at use time will encounter mismatches between their problems and the support that a system provides. These mismatches will lead to breakdowns, which serve as potential sources for new insights, new knowledge, and new understanding. Meta-design advocates a shift in focus from finished products or complete solutions to conditions for users to resolve mismatches and repair breakdowns when they are discovered during use.

Meta-design extends the traditional model of system development consisting of fixed stages to include an ongoing process in which stakeholders become co-designers - not only at design time but also throughout the whole existence of the system. A necessary, although not sufficient, condition for users to become co-designers is that software systems include advanced features (direct activation tools and design environments) that permit users to create complex customizations and extensions to existing systems. Rather than presenting users with closed systems, meta-design approaches provide them with opportunities, tools, and social reward structures to extend the system to fit their needs. Moreover, meta-design is a design methodology that involves multiple stakeholders. One of its objectives in its effort to overcome borders is to make all voices heard. An interesting challenge from this point of view is how to integrate the contributing voices originating from individual and social perspectives.

Meta-design covers the middle ground between general purpose programming languages (Turing Tar Pit) and over-specialized (turnkey) systems. Users need access to a middle ground of abstractions-lightweight but powerful tools and techniques that shorten the edit-compile-debug cycle of conventional programming. To modify a computer application, users should increase their knowledge only by an amount proportional to the complexity of the modification. This has been conceptualized as the "gentle slope" to programming, providing end-user developers with increasingly complex design environments for making changes. 
Our evolving meta-design framework pays attention to motivation, specifically including the following aspects [Fischer et al., 2004b]:

- making changes must seem possible for the skill and experience level of specific users [Scharff, 2002];

- changes must be technically possible (a central objective of our metadesign approach) [Fischer \& Giaccardi, 2004];

- benefits must be perceived; that is, individuals must perceive a direct benefit in contributing that is large enough to outweigh the effort [Grudin, 1987];

- the effort required to contribute must be minimal so that it will not interfere with getting the real work done [Carroll \& Rosson, 1987].

Social creativity needs the "synergy of many," and this kind of synergy is facilitated by meta-design. However, a tension exists between creativity and organization. A defining characteristic of social creativity is that it transcends individual creativity and thus requires some form of organization. On the one hand, elements of organization can and frequently do stifle creativity [Florida, 2002]. On the other hand are historical precedents that too many voices can be worse than having a few choices. As a prime example, the multiparty system that existed in the Weimar Republic in Germany after World War I created a less stable political system compared to countries with a limited number of political parties.

The open systems created by metadesign (a) promote the transcendence of the individual mind; (b) support the users' engagement in the collaborative construction and sharing of meaningful activities; and (c) enable the mutual adaptation and continuous evolution of users and systems by letting users modify the system at use time and adapt it to their dynamic practices.

\section{Socio-Technical Environments: Exploiting Trade-Offs to Enhance Creativity}

In the last decade, L3D has developed socio-technical environments to support the partial resolutions between the binary choices indicated in Table 1. Socio-technical environments can be characterized as follows: (1) They are needed because the deep and enduring changes of our ages are not technological but are social and cultural, in their core substance. Changes in complex environments are not primarily determined by technology, but are the result of incremental shifts in human behavior and social organization. (2) They are composed not only of computers, networks, and software, but also of people, processes, policies, laws, institutions, the flow of design materials and commodities, and many other aspects of a complex web of socio-cultural concerns. (3) They require a co-design of social and technical systems and use models and concepts that not only focus on the 
artifact, but exploit the social context in which the systems will be used. Meta-design is a critical component for socio-technical environments because it gives the users design power to modify and evolve the technical systems according to their needs. The following brief examples of sociotechnical environments deal with specific binary choices and their respective solutions (in reference to Table 1).

Domain-oriented design environments [Fischer, 1994] integrate construction and argumentation. They support CoPs by allowing them to interact at the level of the problem domain and not only at a computational level. They allow for efficient communication within the community at the expense of making communication and understanding difficult for outsiders. They integrate tool-based assistance (e.g., direct manipulation interfaces with objects grounded in the semantics of the problem domain) with agentbased assistance (e.g., critics and simulation components).

Computational critiquing mechanisms [Fischer et al., 1998] enrich the back-talk of situations, thereby increasing the users' understanding of problems by pointing out significant design situations and locating relevant information in large information spaces. Critics afford learning on demand by letting designers access new knowledge in the context of actual problem situations. Critics instantiate and transcend Schön's theory of design [Fischer \& Nakakoji, 1992]; they support "reflection-in-action" and they increase the "back-talk" of the design situation, which in Schön's framework is determined by the designers' skill, experience, and attention [Schön, 1983]. Critics explore and support the trade-offs between (1) serendipity and relevance to the task at hand, (2) information access and information delivery, and (3) new collaboration models between human and computational support.

The Envisionment and Discovery Collaboratory [Arias et al., 2000] supports CoIs with an environment in which participants collaboratively solve problems of mutual interest. The problem contexts explored in the collaboratory, such as urban transportation planning, flood mitigation, and building design, are all examples of open-ended design problems. The sociotechnical environment empowers users to act as designers in problemsolving activities by supporting face-to-face collaboration (see Figure 4). It allows users to engage in complex design tasks by supporting them to incrementally articulate their ideas and negotiate with each other to create mutually agreeable design plans. With the Envisionment and Discovery Collaboratory, new relationships between individual and social creativity [Fischer et al., 2005] can be explored. 


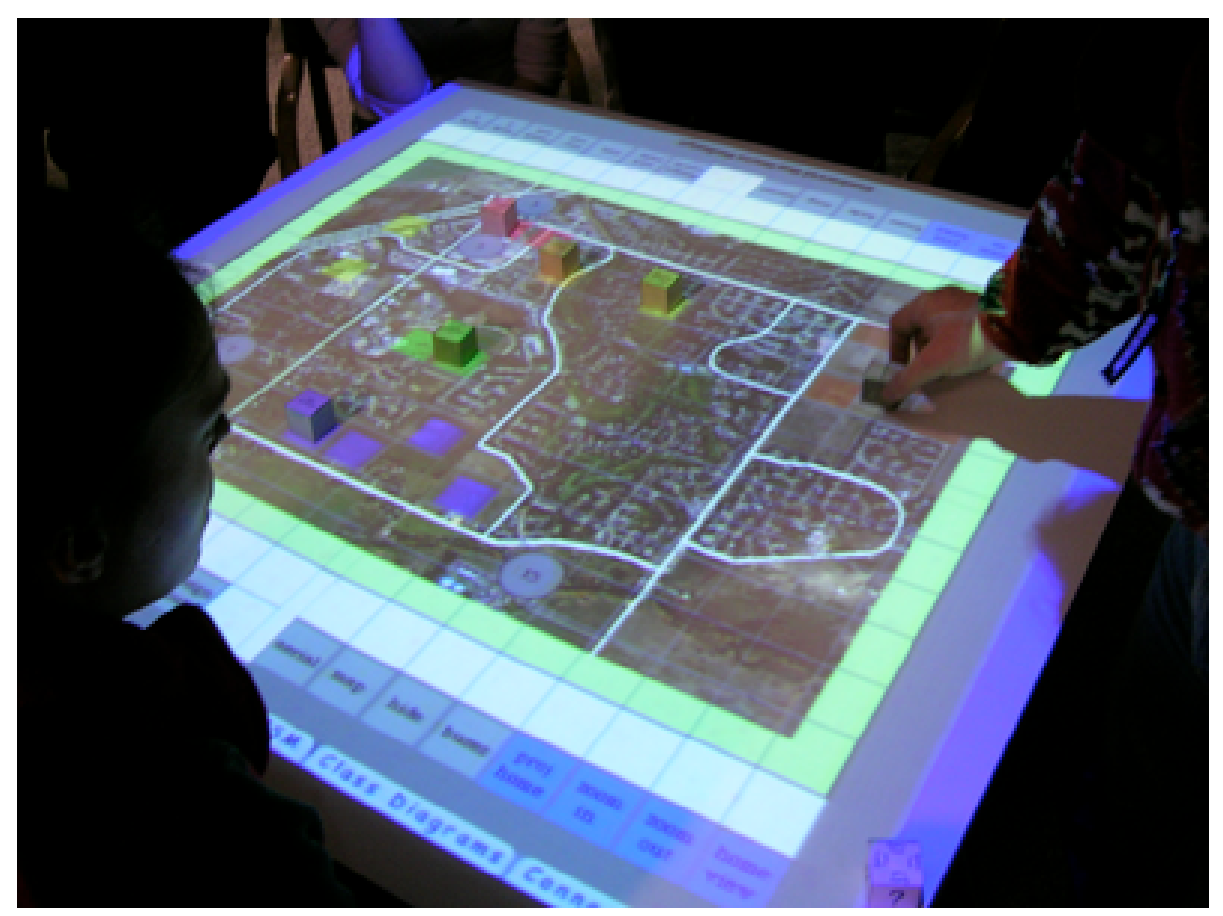

Figure 4: The Envisionment and Discovery Collaboratory

CodeBroker [Ye, 2001] (a reuse support system specifically addressing temporal distance) creates awareness of each other's work so that efforts are not wasted and people can focus on what has not been done before. CodeBroker monitors software developers' programming activities, infers their immediate programming task by analyzing semantic and syntactic information contained in their working products, and actively delivers taskrelevant and personalized reusable parts [Fischer et al., 1998] from a reuse repository created by decomposing existing software systems. CodeBroker will be further developed as an open source software system [Raymond \& Young, 2001] to support the collaboration of a large number of developers. CodeBroker explores our integrated approaches of reflection-in-action, mixed-initiative interactions, and socio-technical environments.

Courses-as-Seeds [dePaula et al., 2001] is an educational model with the goal to create a culture of informed participation that is situated in the context of university courses and yet extends beyond the temporal boundaries of semester-based classes. Courses are conceptualized as seeds, rather than as finished products, and students are encouraged and supported as knowledge workers who play an active role in defining what they will learn. From the courses-as-seeds standpoint, the role of technology is to form and sustain active communities of learners who can make their voices 
heard by contributing ideas from their own unique viewpoints and to connect them in new ways. From this perspective, mere access to existing information and knowledge (e.g., seeing courses as finished products, either in the classroom or on the Web) is a very limiting concept. The courses-asseeds framework explores issues and challenges associated with metadesign, the trade-offs between consumer and producer cultures (see Figure 1 and Figure 2), and the synergy between individual and social creativity.

\section{Conclusions}

Creativity is a multi-faceted concept. Creative people often combine personality traits that are in conflict with each other [Csikszentmihalyi, 1996]. Socio-technical environments enhancing creativity must support not only one end of the spectrum of binary choices, but also - depending on the domain, tasks, and objectives of the people - must exploit trade-offs in a situated fashion to come as close as possible to the "sweet-spot" for a particular situation. This paper has described some of the trade-offs that we have explored in our research over the last decade and the systems that we have built to gain a deeper understanding of creativity and to support creative people.

\section{Acknowledgments}

The author thanks the members of the Center for LifeLong Learning \& Design (L3D) at the University of Colorado, who have made major contributions to the ideas, frameworks, and systems discussed in this paper. The reviewers of this paper have provided valuable feedback leading to this final version.

The research was supported by (1) the National Science Foundation, grants (a) REC-0106976 'Social Creativity and Meta-Design in Lifelong Learning Communities,' and (b) CCR-0204277 'A Social-Technical Approach to the Evolutionary Construction of Reusable Software Component Repositories'; (2) SRA Key Technology Laboratory, Inc., Tokyo, Japan; and (3) the Coleman Institute, University of Colorado, Boulder.

\section{References}

Arias, E. G., Eden, H., Fischer, G., Gorman, A., \& Scharff, E. (2000) "Transcending the Individual Human Mind - Creating Shared Understanding through Collaborative Design," ACM Transactions on Computer Human-Interaction, 7(1), pp. 84-113.

Basalla, G. (1988) The Evolution of Technology, Cambridge University Press, New York.

Bennis, W., \& Biederman, P. W. (1997) Organizing Genius: The Secrets of Creative Collaboration, Perseus Books, Cambridge, MA.

Bobrow, D. G. (1991) "Dimensions of Interaction," AI Magazine, 12(3), pp. 64-80.

Boehm, B., \& Turner, R. (2004) Balancing Agility and Discipline, Addison Wesley, Boston. 
Bonifacio, M., \& Molani, A. (2003) "The Richness of Diversity in Knowledge Creation: An Interdisciplinary Overview," Proceedings of I-KNOW'03, Graz, Austria, pp. 379-388.

Brown, J. S., \& Duguid, P. (1991) "Organizational Learning and Communities-of-Practice: Toward a Unified View of Working, Learning, and Innovation," Organization Science, 2(1), pp. 40-57.

Brown, J. S., \& Duguid, P. (2000) The Social Life of Information, Harvard Business School Press, Boston, MA.

Brown, J. S., Duguid, P., \& Haviland, S. (1994) "Toward Informed Participation: Six Scenarios in Search of Democracy in the Information Age," The Aspen Institute Quarterly, 6(4), pp. 49-73.

Bruner, J. (1960) The Process of Education, Random House, New York.

Campbell, D. T. (2005) "Ethnocentrism of Disciplines and the Fish-Scale Model of Omniscience." In S. J. Derry, C. D. Schunn, \& M. A. Gernsbacher (Eds.), Interdisciplinary Collaboration - An Emerging Cognitive Science, Lawrence Erlbaum Associates, Mahwah, NJ, pp. 3-21.

Carmien, S., Dawe, M., Fischer, G., Gorman, A., Kintsch, A., \& Sullivan, J. F. (2004) "SocioTechnical Environments Supporting People with Cognitive Disabilities Using Public Transportation," Transactions on Human-Computer Interaction (ToCHI), p. (in press).

Carroll, J. M., \& Rosson, M. B. (1987) "Paradox of the Active User." In J. M. Carroll (Ed.), Interfacing Thought: Cognitive Aspects of Human-Computer Interaction, The MIT Press, Cambridge, MA, pp. 80-111.

Clark, H. H., \& Brennan, S. E. (1991) "Grounding in Communication." In L. B. Resnick, J. M. Levine, \& S. D. Teasley (Eds.), Perspectives on Socially Shared Cognition, American Psychological Association, pp. 127-149.

Csikszentmihalyi, M. (1996) Creativity - Flow and the Psychology of Discovery and Invention, HarperCollins Publishers, New York, NY.

Csikszentmihalyi, M., Rathunde, K., \& Whalen, S. (1993) Talented Teenagers: The Roots of Success and Failure, Cambridge University Press, New York.

dePaula, R., Fischer, G., \& Ostwald, J. (2001) "Courses as Seeds: Expectations and Realities," Proceedings of the Second European Conference on Computer-Supported Collaborative Learning (Euro-CSCL' 2001), Maastricht, Netherlands, pp. 494-501.

Derry, S., \& Fischer, G. (2005) Toward a Model and Theory for Transdisciplinary Graduate Education, Available at http://13d.cs.colorado.edu/ gerhard/papers/2005/aeramontreal.pdf

Derry, S. J., Schunn, C., \& Gernsbacher, M. A. (Eds.) (2005) Interdisciplinary Collaboration: An Emerging Cognitive Science, Lawrence Erlbaum Associates, Mahwah, NJ.

Dewey, J. (1967) The School and Society, University of Chicago Press, Chicago, IL.

Ehn, P. (1988) Work-Oriented Design of Computer Artifacts, second ed., Arbetslivscentrum, Stockholm.

Ellis, C. A., Gibbs, S. J., \& Rein, G. L. (1991) "Groupware: Some Issues and Experiences," Communications of the ACM, 34(1), pp. 38-58.

Engeström, Y. (2001) "Expansive Learning at Work: Toward an Activity Theoretical Reconceptualization," Journal of Education and Work, 14(1), pp. 133-156.

Fischer, G. (1994) "Domain-Oriented Design Environments," Automated Software Engineering, 1(2), pp. 177-203.

Fischer, G. (1998) "Making Learning a Part of Life-Beyond the 'Gift-Wrapping' Approach of Technology." In P. Alheit, \& E. Kammler (Eds.), Lifelong Learning and Its Impact on Social and Regional Development, Donat Verlag, Bremen, pp. 435-462.

Fischer, G. (2001a) "External and Sharable Artifacts as Sources for Social Creativity in Communities of Interest." In J. S. Gero, \& M. L. Maher (Eds.), Computational and 
Cognitive Models of Creative Design V, Key Centre of Design Computing and Cognition, University of Sydney, Australia, pp. 67-89.

Fischer, G. (2001b) "External and Shareable Artifacts as Opportunities for Social Creativity in Communities of Interest," Proceedings of the Fifth International Conference on Computational and Cognitive Models of Creative Design, University of Sydney, Australia, pp. 67-89.

Fischer, G. (2002) Beyond 'Couch Potatoes': From Consumers to Designers and Active Contributors, in FirstMonday (Peer-Reviewed Journal on the Internet), Available at http://firstmonday.org/issues/issue7_12/fischer/.

Fischer, G. (2005) "Distances and Diversity: Sources for Social Creativity," Proceedings of Creativity \& Cognition, London, April, pp. 128-136.

Fischer, G., \& Giaccardi, E. (2004) "Meta-Design: A Framework for the Future of End User Development." In H. Lieberman, F. Paternò, \& V. Wulf (Eds.), End User Development Empowering People to Flexibly Employ Advanced Information and Communication Technology, Kluwer Academic Publishers, Dordrecht, The Netherlands.

Fischer, G., Giaccardi, E., Eden, H., Sugimoto, M., \& Ye, Y. (2005) "Beyond Binary Choices: Integrating Individual and Social Creativity," International Journal of HumanComputer Studies (IJHCS) Special Issue on Computer Support for Creativity (E.A. Edmonds \& L. Candy, Eds.), 63(4-5), pp. 482-512.

Fischer, G., Giaccardi, E., Ye, Y., Sutcliffe, A. G., \& Mehandjiev, N. (2004a) "Meta-Design: A Manifesto for End-User Development," Communications of the ACM, 47(9), pp. 33-37.

Fischer, G., Grudin, J., McCall, R., Ostwald, J., Redmiles, D., Reeves, B., \& Shipman, F. (2001) "Seeding, Evolutionary Growth and Reseeding: The Incremental Development of Collaborative Design Environments." In G. M. Olson, T. W. Malone, \& J. B. Smith (Eds.), Coordination Theory and Collaboration Technology, Lawrence Erlbaum Associates, Mahwah, NJ, pp. 447-472.

Fischer, G., \& Nakakoji, K. (1992) "Beyond the Macho Approach of Artificial Intelligence: Empower Human Designers - Do Not Replace Them," Knowledge-Based Systems Journal, Special Issue on AI in Design, 5(1), pp. 15-30.

Fischer, G., Nakakoji, K., Ostwald, J., Stahl, G., \& Sumner, T. (1998) "Embedding Critics in Design Environments." In M. T. Maybury, \& W. Wahlster (Eds.), Readings in Intelligent User Interfaces, Morgan Kaufmann, San Francisco, pp. 537-559.

Fischer, G., Scharff, E., \& Ye, Y. (2004b) "Fostering Social Creativity by Increasing Social Capital." In M. Huysman, \& V. Wulf (Eds.), Social Capital and Information Technology, MIT Press, Cambridge, MA, pp. 355-399.

Florida, R. (2002) The Rise of the Creative Class and How It's Transforming Work, Leisure, Community and Everyday Life, Basic Books, New York.

Friedman, T. L. (2005) The World is Flat: A Brief History of the Twenty-First Century, Farrar, Straus and Giroux, New York.

Greenbaum, J., \& Kyng, M. (Eds.) (1991) Design at Work: Cooperative Design of Computer Systems, Lawrence Erlbaum Associates, Hillsdale, NJ.

Grudin, J. (1987) "Social Evaluation of the User Interface: Who Does the Work and Who Gets the Benefit?" In H. Bullinger, \& B. Shackel (Eds.), Proceedings of INTERACT'87, 2nd IFIP Conference on Human-Computer Interaction (Stuttgart, FRG), North-Holland, Amsterdam, pp. 805-811.

Hippel, E. v. (2005) Democratizing Innovation, MIT Press, Cambridge, MA.

Hirsch, E. D. (1996) The Schools We Need And Why We Don't Have Them, Doubleday, New York.

Horvitz, E. (1999) "Principles of Mixed-Initiative User Interfaces." In Human Factors in Computing Systems, CHI'99 (Pittsburgh, PA), ACM, New York, pp. 159-166. 
Illich, I. (1973) Tools for Conviviality, Harper and Row, New York.

Janis, I. (1972) Victims of Groupthink, Houghton Mifflin, Boston.

John-Steiner, V. (2000) Creative Collaboration, Oxford University Press, Oxford, UK.

Lemke, A. C. (1989) Design Environments for High-Functionality Computer Systems, Ph.D. Dissertation, University of Colorado at Boulder.

Levy, F., \& Murnane, R. J. (2004) The New Division of Labor: How Computers are Creating the Next Job Market, Princeton University Press, Princeton, NJ.

Lieberman, H., Paterno, F., \& Wulf, V. (Eds.) (2005) End User Development - Empowering People to Flexibly Employ Advanced Information and Communcation Technology, Kluwer Publishers, Dordrecht, The Netherlands.

Mandl, H., \& Lesgold, A. (1988) Learning Issues for Intelligent Tutoring Systems, SpringerVerlag, New York.

Mayer, R. E. (2004) "Should There Be a Three-Strikes Rule Against Pure Discovery Learning? - The Case for Guided Methods of Instruction," American Psychologist, 59(1), pp. 14-19.

Mumford, E. (1987) "Sociotechnical Systems Design: Evolving Theory and Practice." In G. Bjerknes, P. Ehn, \& M. Kyng (Eds.), Computers and Democracy, Avebury, Brookfield, VT, pp. 59-77.

National-Research-Council (1999) Being Fluent with Information Technology, National Academy Press, Washington, DC.

National-Research-Council (2003) Beyond Productivity: Information Technology, Innovation, and Creativity, National Academy Press, Washington, DC.

Norman, D. A. (1993) Things That Make Us Smart, Addison-Wesley Publishing Company, Reading, MA.

Olson, G. M., Malone, T. W., \& Smith, J. B. (Eds.) (2001) Coordination Theory and Collaboration Technology, Lawrence Erlbaum Associates, Mahwah, NJ.

Ong, W. J. (1982) Orality and Literacy, Routledge, London.

Raymond, E. S., \& Young, B. (2001) The Cathedral and the Bazaar: Musings on Linux and Open Source by an Accidental Revolutionary, O'Reilly \& Associates, Sebastopol, CA.

Resnick, L. B., Levine, J. M., \& Teasley, S. D. (Eds.) (1991) Perspectives on Socially Shared Cognition, American Psychological Association, Washington, DC.

Roberts, R. M. (1989) Serendipity: Accidental Discoveries in Science, John Wiley \& Sons, New York.

Rogoff, B., Matsuov, E., \& White, C. (1998) "Models of Teaching and Learning: Participation in a Community of Learners." In D. R. Olsen, \& N. Torrance (Eds.), The Handbook of Education and Human Development - New Models of Learning, Teaching and Schooling, Blackwell, Oxford, UK, pp. 388-414.

Schank, R. C., \& Abelson, R. P. (1977) Scripts, Plans, Goals, and Understanding, Lawrence Erlbaum Associates, Hillsdale, NJ.

Scharff, E. (2002) Open Source Software, a Conceptual Framework for Collaborative Artifact and Knowledge Construction, Ph.D. Dissertation, University of Colorado at Boulder.

Schön, D. A. (1983) The Reflective Practitioner: How Professionals Think in Action, Basic Books, New York.

Shneiderman, B. (2002) Leonardo's Laptop - Human Needs and the New Computing Technologies, MIT Press, Cambridge, MA.

Shneiderman, B., \& Maes, P. (1997) "Direct Manipulation vs. Interface Agents," Interactions $(A C M), 4(6$ (Nov)), pp. $42-61$.

Simon, H. A. (1996) The Sciences of the Artificial, third ed., The MIT Press, Cambridge, MA. 
Snow, C. P. (1993) The Two Cultures, Cambridge University Press, Cambridge, UK.

Star, S. L. (2005) "Categories and Cognition: Material and Conceptual Aspects of LargeScale Category Systems." In S. J. Derry, C. D. Schunn, \& M. A. Gernsbacher (Eds.), Interdisciplinary Collaboration - An Emerging Cognitive Science, Lawrence Erlbaum Associates, Mahwah, NJ, pp. 167-186.

Turkle, S., \& Papert, S. (1991) "Epistemological Pluralism and the Revaluation of the Concrete." In I. Harel, \& S. Papert (Eds.), Constructionism, Ablex Publishing Corporation, Norwood, NJ, pp. 161-191.

Wenger, E. (1998) Communities of Practice - Learning, Meaning, and Identity, Cambridge University Press, Cambridge, UK.

Ye, Y. (2001) Supporting Component-Based Software Development with Active Component Repository Systems, Ph.D. Dissertation, University of Colorado at Boulder.

Ye, Y., \& Fischer, G. (2005) "Reuse-Conducive Development Environments," International Journal Automated Software Engineering, Kluwer Academic Publishers, Dordrecht, Netherlands, 12(2), pp. 199-235. 